\title{
O LUGAR DO DESENVOLVIMENTO NA MOBILIZAÇÃO SOCIAL: SIGNOS DE DESENVOLVIMENTO E PRODUÇÃO DE UTOPISMOS NAS JORNADAS DE JUNHO DE 2013
}

\author{
Gustavo Souza Santos ${ }^{1}$ \\ Anete Marília Pereira ${ }^{2}$
}

\section{Resumo}

Este estudo refletiu a relação entre os signos de desenvolvimento e produção de utopismos nos objetos e ideais das mobilizações sociais, tendo por quadro de análise as Jornadas de Junho de 2013 no Brasil. Metodologicamente, considerou-se um estudo de caso por meio de análise documental de jornais impressos apurados com maior tiragem no período, considerando como corpus a cobertura jornalística do período a partir das categorias de demandas emergentes dos atos. Esse novo desenho de articulação popular indica uma flexão da participação, onde as territorialidades de insurgência são tessituras de coalizão e desenvolvimento(s). A ressonância da voz reivindicatória popular em rede indica a subversão das assimetrias do desenvolvimento ou, pelo menos, um sinal de que a planificação do conceito encontra impasses maiores. Microdesenvolvimento é o início de uma discussão possível sobre o quadro atual de ativismos em rede e seu significado ainda provocador acadêmica, política e socialmente.

Palavras-chave: Mobilização popular. Desenvolvimento social. Utopismo. Jornadas de Junho.

\section{THE PLACE OF DEVELOPMENT IN SOCIAL MOBILIZATIONS: SIGNS OF DEVELOPMENT AND UTOPIANISM PRODUCTION IN BRAZILIAN'S JUNE DAYS IN 2013}

\begin{abstract}
This study reflected the relationship between the signs of development and the production of utopianism in the objects and ideals of social mobilizations, with the analysis of the Journeys of June 2013 in Brazil. Methodologically, it was considered a case study by means of documentary analysis of printed newspapers with the highest circulation in the period, considering as corpus the journalistic coverage of the period from the categories of demands emerging from the acts. This new design of popular articulation indicates a flexion of participation, where territorialities of insurgency are coalition and development(s). The resonance of the popular claiming voice in a network indicates the subversion of developmental asymmetries or at least a sign that concept planning encounters major impasses. Microdevelopment is the beginning of a possible discussion about the current picture of network activism and its still provocative significance academically, politically, and socially.
\end{abstract}

Keywords: Popular mobilization. Social development. Utopianism. June Days.

\footnotetext{
${ }^{1}$ Doutorado e mestrado em Ecologia e Conservação pela Universidade Federal do Paraná, UFPR. Email: gustavo.ccpv@gmail.com

${ }^{2}$ Doutorado em Geografia pela Universidade Federal de Uberlândia, mestrado em Geografia pela Universidade Federal de Minas Gerais, especialização em Geografia e Planejamento Ambiental pela PUC/MG.
} 
O lugar do desenvolvimento na mobilização social: signos de desenvolvimento e produção de utopismos nas jornadas de junho de 2013

\section{EL LUGAR DE DESARROLLO EN LA MOVILIZACIÓN SOCIAL: SIGNOS DE DESARROLLO Y PRODUCCIÓN DE UTOPISMOS EN LAS MANIFESTACIONES DE JUNIO DE 2013}

\section{Resumen}

Este estudio reflejó la relación entre los signos de desarrollo y producción de utopismos en los objetos e ideales de las movilizaciones sociales, teniendo como marco de análisis los días de junio de 2013 en Brasil. Metodológicamente, se consideró un estudio de caso mediante análisis documental de periódicos impresos encontrados con mayor circulación en el período, considerando como corpus la cobertura periodística del período de las categorías de demandas que surgen de los actos. Este nuevo diseño de articulación popular indica una flexión de participación, donde las territorialidades de la insurgencia son hilos de coalición y desarrollo. La resonancia de la voz demandada popular en la red indica la subversión de las asimetrías de desarrollo o, al menos, una señal de que la planificación del concepto encuentra mayores impases. El microdesarrollo es el comienzo de una posible discusión sobre la situación actual del activismo en red y su significado aún provocador académica, política y socialmente.

Palabras clave: Movilización popular. Desarrollo social El utopismo. Manifestaciones de Junio.

\section{INTRODUÇÃO}

Entre a dimensão simbólica do desenvolvimento - que carrega promessas localizadas e o ensejo utópico do engajamento popular insurgente ante a transformação social, há a construção de um plano ideal, um lugar do desenvolvimento, onde o bem viver, os projetos de vida e país se realizam plenamente, e tal dimensão está interpolada na constituição das mobilizações sociais, especialmente aquelas produzidas em rede.

O caráter multidimensional do desenvolvimento (BERTONCELLO, 2011; IVO, 2012) abriga uma arena simbólica, onde forças políticas, econômicas e sociais são atravessadas e consubstanciadas por um aparato sígnico e retórico. Esse constructo semântico e sígnico do desenvolvimento é assimétrico, isto é, disputado por hegemonias e exercícios populares (ESTEVA, 2000)

O desenvolvimento como meta e programa se desdobra em visões, práticas e, consequentemente, promessas. Essas promessas pelo bem vindouro são relacionais, pessoais, coletivas, públicas e privadas. Tais promessas se constituem de signos (imagens mediadoras). Desse modo, no ideário do desenvolvimento, geram-se imaginários, representações e discursos de imagens aspiradas e tensionadas na realidade. 
As Jornadas de Junho de 2013 despontaram no Brasil como manifestações partícipes de novas mobilizações populares desdobradas em diversas partes do mundo na última década. Multiescalares, horizontais, voláteis e reticuladas, essas pulsões insurgentes trazem para o chão da insurgência demandas diversas, pulverizadas.

A proposta deste estudo foi refletir a relação entre os signos de desenvolvimento e produção de utopismos nos objetos e ideais das mobilizações sociais, tendo por quadro de análise as Jornadas de Junho de 2013 no Brasil. Metodologicamente, considerou-se um estudo de caso por meio de análise documental.

Como empiria para a aproximação proposta desse objetivo, partiu-se do que os protestos vocalizaram como demandas, reivindicações e ideais. Entende-se aqui que o ideário em torno dos objetos de luta designa instâncias coletivas (participação sociopolítica e identidades coletivas). Para catalogar as demandas, recorreu-se à narrativa feita das manifestações em caso.

Considerou-se como fonte de dados, o conteúdo noticioso de jornais impressos. Partiuse dos veículos de maior circulação no período das manifestações, isto é, de 17 a 30 de junho de $2013^{3}$, sob auditoria do Instituto Verificador da Comunicação (IVC/ANJ) ${ }^{4}$ para o período supracitado. Os jornais de maior circulação, conforme apuração, foram Estadão, Folha de S. Paulo e O Globo 5 .

O corpus consistiu do texto das matérias e da cobertura dos veículos que expressavam as reivindicações da população mobilizada, dos quais a leitura fez destacar as principais categorias ou teores de demandas reivindicatórias dos atos. A partir dos dados, apurou-se também dados quantitativos dos atos para produção cartográfica.

Inicialmente, discute-se a odisseia polissêmica do termo desenvolvimento, discutindoo como uma categoria política, mas sobretudo retórica. A seguir, reflete-se o termo desenvolvimento no contexto das mobilizações sociais, como se coadunam demandas retóricas e o fragor do desenvolvimento. E, por fim, examinam-se o caso em estudo, discutindo suas premissas, demandas e o lugar do desenvolvimento em sua conjuntura insurgente.

\footnotetext{
${ }^{3}$ Período em que se convenciona chamar de Jornadas de Junho. Flexões anteriores ou posteriores não se enquadram no escopo ou configuração dos atos em questão.

${ }^{4} \mathrm{~A}$ informação foi fornecida pela própria instituição, a partir de carta que apresentava o interesse do estudo. A decisão pelo critério de circulação se dá pela possibilidade de cobertura jornalística e distribuição do veículo pelo território nacional, implicando em maior apreensão e abrangência, não apenas logística, mas de leitores assinantes ou espontâneos.

${ }^{5}$ Em adendo à cobertura numérica dos protestos analisados, dados do portal G1 foram utilizados.
} 
O lugar do desenvolvimento na mobilização social: signos de desenvolvimento e produção de utopismos nas jornadas de junho de 2013

\section{DESENVOLVIMENTO COMO ESQUEMA SEMÂNTICO: A TRAJETÓRIA DE UMA RETÓRICA SOCIOPOLÍTICA}

O desenvolvimento como necessidade e programa é tido por articulação do Estado e de forças populares colaborativamente. Mas, para além dessa visão institucionalizada e formal, há aspirações no que toca à voz popular. Quando grupos se põem em luta, suas reivindicações e demandas são tessituras de desenvolvimento disputando a formalidade mecanicista do conceito.

Enquanto programas nacionais ou regionais são interpostos, no limiar popular, há um ensejo que reclama a construção de um programa virtual, isto é, residente na experiência cotidiana. Os arrochos e os contextos expressos nos indicadores e nos programas de ação têm senda simbólica e vivencial gráfica aqui.

As vozes postas nas ruas, nos grupos ou nas timelines são disputas pela direção do curso do programa de desenvolvimento atrelado à noção contemporânea de viver democraticamente em um Estado de Direito. As disparidades interpolam as vivências, onde viver em meio à desigualdades é questionar o status do que se vê, entende e endossa por direção do desenvolvimento.

As demandas frequentemente reclamam cenários já conhecidos no imaginário popular e nos repositórios midiáticos: são aspectos sociais, econômicos, políticos, de acesso, distribuição e reconhecimento. E essas demandas não são reclamações esgarçadas e automatizadas do imaginário.

Essa carga reivindicatória está aditivada pelo elemento simbólico do dano, da perda, da disparidade, das desigualdades e do arrocho social vivenciada no terreno da realidade cotidiana. E, como que em reflexo, as benesses dos programas sociopolíticos de desenvolvimento que encerram promessas se tornam insatisfatórias.

O que se vocaliza torna-se mais do que querela, mas reforço de uma inconformidade com os modelos de participação, destarte o enfoque contumaz aos direitos sociais em detrimento dos políticos, e naturalmente, de seu exercício. Cidadania e participação estão diante de questionamentos (CANCLINI, 2006).

A terminologia desenvolvimento é paradoxalmente poderosa, portentosa, frágil e problemática (IVO, 2012). Historicamente, emerge um conceito que explica, tal qual um oráculo sobre o destino humano, as ações que devem nortear as sociedades modernas a um ponto de anelo e crescimento servidor do eixo capitalista de produção da vida (BERTONCELO, 2013). 
O poder do termo está em sua capacidade de concatenar agendas globais a um ponto de convergência social, econômica e política, com mobilizações robustas de recursos e afetos. O sentido biológico do vocábulo que, na perspectiva darwinista, indicava um movimento continuado de uma condição para uma outra forma, mais apropriada, ganhou o sentido evolutivo de uma forma sempre perfeita a perseguir (ESTEVA, 2000).

Ora, o préstimo biológico consistiu uma metáfora eloquente em que a história se tornou um programa no qual seu curso deve ser manufaturado, ajustado e produzido de modo a se adequar ao ideário do desenvolvimento, um patamar de progresso, um destino escatológico onde repousariam as benesses humanas da vida social, econômica e política.

O esquema semântico do desenvolvimento tornou-se uma armadilha retórica por inflexão. Ao assumir a envergadura evolutiva de uma forma - sendo rudimentar ou não - precisa chegar a um estágio perfeito, criou-se um dispositivo de captura de interesses e esforços mobilizados, onde esse estágio perfeito é sempre controlado ou redefinido nos pleitos de poder.

Todavia, a fragilidade do termo reside justamente em seu jogo semântico. A absorção de significados tornou o termo impreciso e suscetível para que agendas políticas e mercadológicas o cooptassem como instrumento colonial ou de aceno à manutenção de hegemonias. O significado foi a instabilidade sobre o resíduo do desenvolvimento.

Essa forma perfeita no qual o desenvolvimento encontra seu gozo é o pleito de seu emprego em programas distintos, idealizados e praticados em instâncias diversas: estatais, mercadológicas, populares e outras. Originou-se um mito explicativo sobre a realidade - o desenvolvimento não alcançado - e descritivo de seu rumo - uma evolução a perseguir (RIST, 2002).

Residualmente, produziu-se uma tensão pela meta, um ponto alcançável, parametrizado e situado em um estágio pleno do qual não se atinge facilmente ou que nações-modelo alcançaram e, portanto, devem ser imitadas. Essa tensão criou uma ambiência em torno do termo, no qual se produzem as mais diversas narrativas arraigadas no vácuo de uma ansiedade pelo status de desenvolvido diante de um desenho de difícil operacionalização na prática.

Essa ambiência do desenvolvimento é firme e se sustenta a partir da literatura produzida desde longa data sobre as discussões que desdobram a partir do tema, além do senso comum, dos afetos e da cultura política e do imaginário mediado pela disputa narrativa entre mídia, instâncias políticas, governanças e mercado. Cria-se uma metanarrativa.

Desse modo, o termo desenvolvimento arrolou-se como um projeto e, simultaneamente, uma meta que aponta direção e explicações da realidade - quando esta não é favorável, um 
O lugar do desenvolvimento na mobilização social: signos de desenvolvimento e produção de utopismos nas jornadas de junho de 2013

quadro deficitário torna-se explicativo. Ora, quando o termo perde relevância nesse esquema, centralidades temáticas assumem maior evidência para alargar a narrativa diante do plano moderno e capitalista de ser, estar, viver e produzir.

A economia é a primeira centralidade temática. A ideia de que todos os elementos de uma sociedade ou uma nação só encontram plenitude ou harmonia diante da estabilidade econômica subjugou as dinâmicas da vida social em sua complexidade e (i)materialidade às práticas produtivas retráteis do capitalismo, mimetizando a vida ao consumo e à produtividade.

Como releitura do termo, o adjetivo social foi incorporado à sua noção. A implicação do termo social era adensar o desenvolvimento tido como imperativo para o crescimento econômico, considerando aspectos sociais como um elemento integrador. A nova compreensão era uma forma de dotar os esforços de um desenvolvimento pensado nos moldes de crescimento econômico lidar eficazmente com obstáculos sociais, entraves à economia.

Destarte o elemento social passasse a tonificar a causa, faltava ainda uma concentração no indivíduo, isto é, que considerasse sua parcela de contribuição. E mais, sua participação. O elemento participativo foi uma tentativa de adição moral ao desenvolvimento que na prática era atroz e pouco acenava para a democracia, no que toca sobretudo a um exercício cidadão e humanista do termo.

Partindo desse pressuposto, novas centralidades como desenvolvimento integrado, endógeno, redesenvolvimento, desenvolvimento sustentável e desenvolvimento humano tomaram partes da narrativa conceitual (ESTEVA, 2000). A prerrogativa é o lugar humano, do indivíduo, do cidadão, da coletividade e toda a multidimensionalidade que isso evoca para além das tratativas puramente econômicas, parametrizadas e formalistas.

A economia, "o social", a cidadania e a liberdade constituíram valores para a tentativa de implantação de um plano de desenvolvimento abrangente, viável e eficaz. Além de adjetivação que enuncia sua tônica propositiva, foram guias morais diante dos dramas socioeconômicos e políticos, os obstáculos à materialização do conceito.

Variáveis sócio-históricas e geográficas também foram possíveis com o desenvolvimento endógeno e sustentável. Porém, todas as iniciativas e concepções partiam de um limiar global ou cuja discussão se espargia na internacionalização. Com o arrefecimento do global e a revalorização do local, as dimensões regionais e territoriais ganharam força na medida em que se tornam fonte de conhecimento e ação para nações, governos e populações.

As relações de governança e as intempéries sociopolíticas tornaram o intento por cases de sucesso uma ideia distante, mesmo reduzindo o escopo ou a cobertura geográfica. É factual 
que o desenvolvimento se consolidou em uma arena que, como tal, pressupõe disputas de narrativa e ação. Ora, confirmou-se a necessidade de que povos e nações pudessem gozar de um bem viver, porém a trajetória e as medidas para tanto se tornaram tão infladas quanto a definição de desenvolvimento.

Esse cenário se deve à construção do desenvolvimento como um plano sobretudo político, mesmo quando novas centralidades e adjetivações parecessem indicar novas sendas e renovada crença em eficiência. A ideia de explorar sociedades e culturas para extrair elementos que construam estruturas ordenadas centradas na economia, mas articuladas como um eixo político e ético (ESTEVA, 2000).

A ambiência do desenvolvimento ainda prevalece sobre qualquer nova ideia, sobretudo crítica, sobre o que está implicado nessa questão. O senso comum já absorveu, por meio da estrutura semântica e retórica do desenvolvimento, que o desfecho do mundo parte de uma leitura econômica. O que isso oculta ao olhar da opinião pública é a colonização de uma lógica mercantil ou amparada em significados cristalizados de uma operacionalização da vida ante ao economicamente crível, plausível.

Os impasses diante do desenvolvimento começam no conjunto sintático e semântico que, por si só, traduzem lógicas de pares opostos e que fazem aspirar contextos ideológicos nos quais os que figuram como fracos, instáveis e rudimentares alcancem o posto de desenvolvido. A estrutura simbólica do termo suplanta a trajetória de esforços uma vez que instala um programa retórico persuasivo o bastante para mobilizar afetos e ideologias em direções políticas programáticas.

Já que o desenvolvimento - aqui brevemente lido como complexo e vertiginosamente multidimensional - se desdobrou como uma arena simbólica aquecida e persuasiva, convém consultar sua estrutura retórica. Nos ditames aristotélicos, a tríade orador, discurso e audiência configuram um circuito de processamento retórico em instâncias e enfoques.

Entretanto, na esteira de construção do desenvolvimento como um campo factual e de estudos (ESTEVA, 2000; RIST, 2002; IVO, 2012; BERTONCELO, 2013), verifica-se que o orador produtor do discurso sempre cumpriu seu papel de um mesmo plano, tendo a audiência por instrumentalização de interesses, naturalmente inerentes à retórica discursiva. Isto é, o poder político e econômico da governança e do mercado sempre assumiram o centro decisório dos rumos do desenvolvimento.

Há uma hegemonia decisória nessa perspectiva, mesmo quando a especialidade acadêmica foi acionada historicamente. No mais populista dos programas e acepções de 
O lugar do desenvolvimento na mobilização social: signos de desenvolvimento e produção de utopismos nas jornadas de junho de 2013

desenvolvimento, fibras de controle hegemônico das análises, interpretações, medidas e avaliações da realidade foram observáveis. O elemento popular era uma peça constitutiva, importante notadamente, mas sem poderes decisórios, ou sem clareza diretiva.

Não obstante os discursos de desenvolvimentos participativos e integrados reclamassem o lugar civil e cidadão, havia sempre uma metabolização das iniciativas para um plano onde o público da esfera pública culminasse em governabilidade e governança, aditivados pelo state of affairs político.

A população na conjugação de massa não foi suficientemente atrelada aos processos que pensaram e construíram o desenvolvimento. Todavia, o popular absorveu os impactos das diversas tentativas, introjetando discursos e organizando seus projetos de vida e visões de mundo a partir dos componentes dos discursos do desenvolvimento.

A complexidade do termo desenvolvimento não esvazia, porém, a relevância dos debates que ele suscita, dadas as exigências da realidade. Há, como já revisitado no conceito, multidimensões: inscrições políticas, sociais, econômicas e culturais. A pauta democrática, porém, ergue outro ponto de discussão, alocada no campo da cidadania, da participação social e do popular, das massas - nem tão inofensivas e cristalizadas como já se teorizou.

\section{DESENVOLVIMENTO NA MOBILIZAÇÃO SOCIAL: O ACONTECER DAS DEMANDAS}

O desenvolvimento e sua teia semântica, partindo da trajetória sociopolítica do conceito, evocam um ponto de chegada, uma meta, um resultado sempre perfeito ou capaz de realizar plenitude. A busca pela definição e pela aplicação do desenvolvimento tornou-se uma saga por uma categoria explicativa de encaixe sobre a realidade, que gerasse conforto por oferecer uma solução social encontrou.

Essa saga encontrou ressonância nos projetos e redefinições de desenvolvimento(s) no tempo e no espaço. As buscas, práticas, aplicações e implementações denotaram um ímpeto por alocar na necessidade de medidas sociopolíticas que solucionassem os impasses modernos de desigualdades e outros déficits. Trata-se, sobretudo, de uma meta, mesmo que o termo ainda seja provocador e insatisfatório no sentido terminológico.

Essa meta é tensa. No contingente histórico de indefinições e mutações, o ensejo, o desejo e as ambiências do desenvolvimento apelam para um lugar onde as aspirações estão diante de impasses que não se realizam facilmente nas promessas da modernidade paradigmática e de pretensiosa revolução total. 
E a modernidade contém signos que se configuram como dinâmicas que alteram ou provocam os devires. A condição moderna evoca uma necessidade premente de que a vida vivida e produzida se conforme à estrutura simbólica do moderno, crescente, revolucionário, tecnológico e eminentemente evolutivo - no sentido de aderência do desenvolvimento.

A sociedade de consumo (BAUMAN, 2008; BAUDRILLARD, 2009), em uma extensão maior do conceito (CANCLINI, 2006) e no que toca a odisseia de narrativas e devires produzidos pela modernidade, tem um papel de destaque na dimensão que o desenvolvimento assume a partir do esgotamento dos planos e das estratégias, mas no que gera atrição à realidade.

Consumir desdobrou-se como uma atividade sociocultural que resume as relações e operações cotidianas. Os produtos, serviços e ideias continuam consumíveis e articulados em ciclos mercadológicos de trocas mais ou menos complexas. Mas a dinâmica da aquisição para suprir um desejo que de volúpia tornou-se necessidade difundiu-se por todos os âmbitos humanos, de modo que o status de consumidor tornou-se uma espécie de navegação social (CANCLINI, 2006).

O consumo em si possui uma retórica portentosa. Na capacidade de consumir, ou na condição de consumidor, experimenta-se uma flexão de poder onde as relações são materializadas e operacionalizadas em mercadorias. Essas mercadorias não compõem apenas o já conhecido fetichismo consumista, mas operam no campo da subjetividade construída a partir do consumo (BAUMAN, 2008).

Esse poder por inflexão do consumo produz signos, aditivados pelas dinâmicas de mercado e pela narrativa publicitária. Esses signos constroem quadros de referência para a produção de performances particulares, mutações nas visões de mundo e de exercício cidadão, onde o poder, o ser, o estar e o fazer na vida em sociedade estão sujeitas a uma performance por escolha simples, como em uma situação prática de consumo.

As estruturas sígnicas produzem imagens relacionais e representações da realidade, seja prática, aspirada ou de ambos. A partir de tais imagens e representações, narrativas são constantemente reelaboradas entre operações internas e externas aos sujeitos e seus grupos. Recuperando a discussão do desenvolvimento como meta tensionada, o poderio simbólico das relações de consumo se torna uma trama combinada de visão e lida da realidade.

A insatisfação social passa a ser pareada à insatisfação que se obtém quando um produto ou serviço não atende bem às expectativas do consumidor. E, no seu direito, o consumidor reclama ao prestador do serviço que corrija ou o compense do problema com o não atendimento imediato do qual se esperou quando do momento da transação. 
O lugar do desenvolvimento na mobilização social: signos de desenvolvimento e produção de utopismos nas jornadas de junho de 2013

Esse sistema de consumo é então aplicado em outras dimensões da vida, simplificando as relações da vida em sociedade o itinerário de consumo. Tudo passa a estar sujeito a essa ordem de desejos tornados necessidades e de imagens relacionais capazes de compor os sujeitos, seus grupos e trajetórias de vida. No consumo está a satisfação de lacunas. E quando a vida passa a ser consumível?

Os signos de consumo e das promessas incrustadas nos ideários de desenvolvimento e nas vitrines de modelos externos ou mesmo do quadro referencial do capitalismo sedutor, geram uma modalidade distinta de insatisfação que reclama participação por um modus operandi que deseja um modus vivendi como prometido nos signos de desenvolvimento.

Apresenta-se um cenário oblíquo onde as necessárias discussões sobre o desenvolvimento e o que ele abarca no afã de uma solução para problemas socioeconômicos, os signos e o próprio consumo como forma de navegação social, e a noção de direitos e participação social diluída nesse contexto.

Esse cenário modifica a estrutura de percepção e vocalização dos anseios populares. As necessidades e desejos em um plano de consumo se imiscuem do terreno dos direitos sociais e, como signos, passam a criar novas pulsões e demandas. Sobretudo no que se entende por mobilização popular, tem-se um quadro particular onde as reivindicações ou entendimento popular das necessidades se mimetizam como atos de consumo.

As reivindicações nascidas no terreno da coletividade ou na identificação de grupo a partir das vivências comuns no mesmo processo de arrocho ou questionamento experimentam um duplo movimento: tornam-se pareadas a atos de consumo como escolhas personalizadas, nas quais se compõem demandas por identificação individual ou de uma comunidade de consumo social; e nesse mesmo embalo, se tornam aspirações sempre mais extensas dado o objeto contingencial da dinâmica de um consumo sempre maior.

E é nesse trânsito de personalização e consumo que direitos, demandas e perspectivas sociais trafegam. Com isso, especula-se aqui que esse prospecto designe novas formas de visão da realidade que indignam e causam celeuma, querelas e reivindicações. Destrava-se um novo tipo de acontecer de demandas que, por sua vez, destrava um novo acontecer de mobilizações populares e, consequentemente, um novo acontecer do desenvolvimento.

A coletividade mobilizadora, nesse contexto, reforça-se na tendência da rede. Ora, as redes não são apenas tessituras que explicam fluxos de ação, isto é, são apenas descritivas de um formato de ação (CASTELLS, 2013). Redes são, antes de tudo, laboratórios de ação. Os 
nós e arcos se formam na medida em que tramas geram e alimentam os fluxos, coletivamente, como laboratórios de potência e agência, deflagradoras do processo de reticulação.

As demandas sociais são percebidas de um modo particular. A rede de sujeitos que se relaciona de modo fetichizado diante da realidade passa a se mobilizar por identificação plural. A diferença liga pela experiência, uma realidade de consumo que passa a designar realidades de movimentação. Todavia, um aspecto se destaca, o apelo pelo gozo do objeto de desejo. Como a demanda social poderia satisfazer tal necessidade?

As demandas mobilizadas denotam aspirações, sonhos, utopismos, projetos de vida e país, ou, uma emulação das forças operacionais do(s) desenvolvimento(s). Portanto, vislumbrase na pulsão reivindicatória, microdesenvolvimentos. O deslocamento do centro de ação parece indicar coalizão.

As múltiplas dimensões, tratativas e tentativas de desenvolvimento constituíram uma nuvem densa de signos que intensificaram os desejos por um lugar nos qual os intentos, os ideais, os utopismos, as promessas e as benesses possam repousar e realizar. Embora imerso em representação e imaginário, o signo é mediador. Logo, a mediação destrava possibilidades de agência, potência e devires (MARTÍN-BARBERO, 2006).

\section{SIGNOS DE MOBILIZAÇÃO, SIGNOS DE DESENVOLVIMENTO: ONDE REPOUSA A TENSÃO}

Em junho de 2013, um quadro particular se delineava. As dimensões do país marcadas pela diversidade territorial e multiplicidade regional foram articuladas em uma pulsão unitária. Os atos, embora em dimensões distintas, detonaram o conteúdo de sua insurgência por meio de uma ativação territorial.

Tal ativação, contudo, não implicou em metabolismos das especificidades das protuberâncias dos dramas sociais dos múltiplos lugares de onde as vozes se aglutinavam em mobilização. Mas, por meio de uma frente relacional, territorialidades episódicas foram capazes de capitanear a diferença e a variedade como em um uníssono identitário.

O movimento começou com a pauta característica do Movimento Passe Livre em torno do transporte público de qualidade e o pleito pela gratuidade do serviço. A querela se inicia com o aumento da tarifa de ônibus em $\mathrm{R} \$ 0,20$, matéria que já vinha sendo discutido pelos militantes junto à administração paulistana. Com o desentendimento, o movimento se pôs às ruas. 
O lugar do desenvolvimento na mobilização social: signos de desenvolvimento e produção de utopismos nas jornadas de junho de 2013

Em flexão solidária e com a difusão do movimento, o escopo se amplia. As vozes passaram a gritar não apenas por mobilidade urbana, mas nesse signo de ir e vir, demandas diversas, conhecidas das vivências e do imaginário popular, passaram a ser ouvidas. Um grito comum era perceptível em cartazes, vozes e postagens: "não é por R\$ 0,20, é por direitos".

A etiqueta de direitos tornou a dinâmica do teor dos atos ainda mais aguçada, exigindo providência de governos, da classe política e a atenção da sociedade civil para contextos de direitos precarizados. Direitos caracterizaram o entendimento das pautas postas em movimento nas ruas, em atos que cobriram 538 municípios, os 26 estados brasileiros e o Distrito Federal, e cerca de 2,7 milhões de manifestantes, como elucida a figura 1 por meio da localização espacial dos atos:

\section{Figura 1: Localização dos protestos}

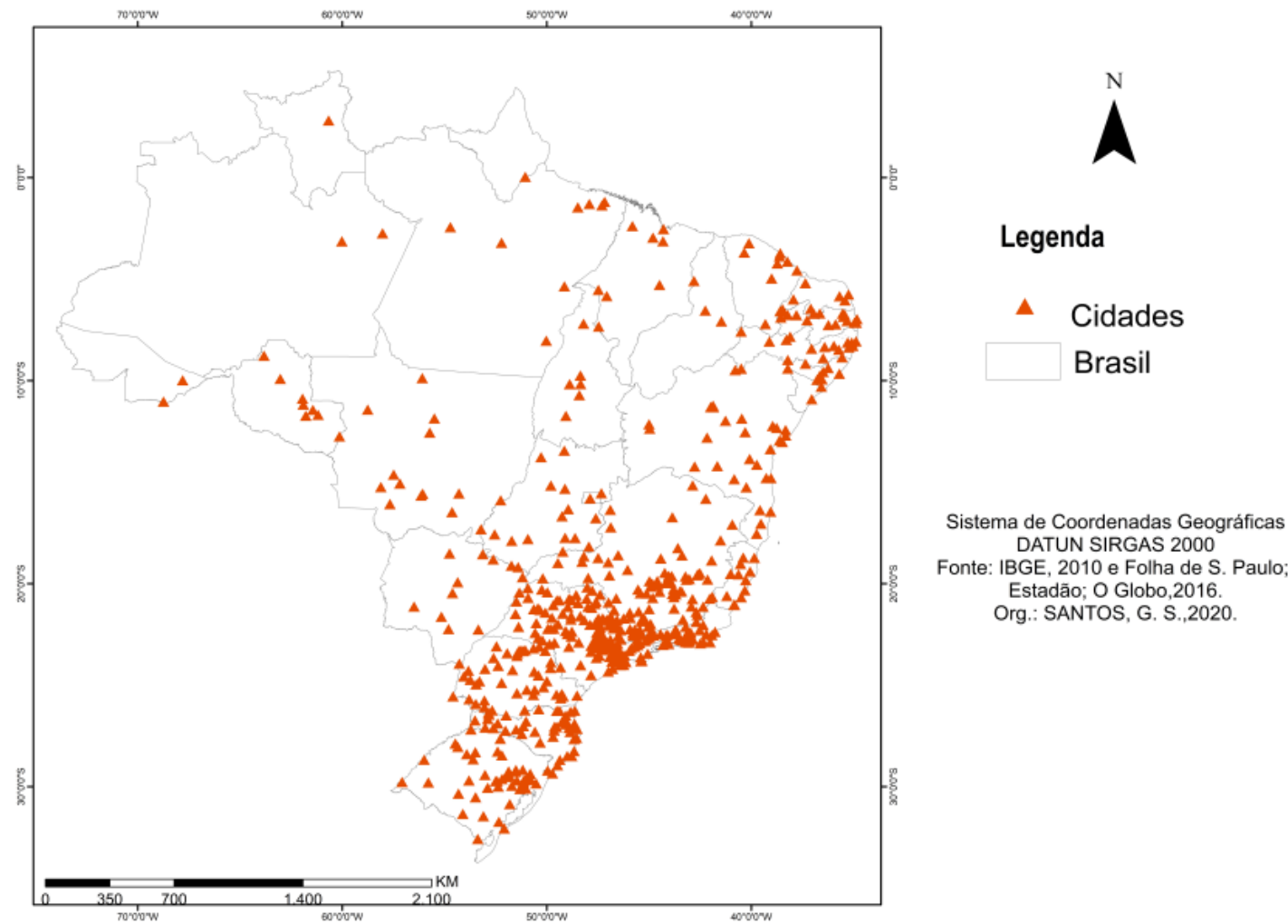

Fonte: Estadão (2013), Folha de S. Paulo (2013), O Globo (2013) e G1.

Catalogou-se 318 notícias sobre as Jornadas de Junho entre os veículos consultados. Das centenas de menções, descrição dos fatos e análises da notícia, emergiram campos de disputa representados por demandas e reivindicações que sinalizassem discursos. Entendendo que as vocalizações de mobilizações sociais acenam e/ou disputam práticas e discursos de desenvolvimento, procurou-se aqui refletir seu teor. 
O quadro 1 agrupa as demandas catalogadas a partir dos atos, coletadas por repetição e saturação entre as notícias catalogadas. Aplicando-se uma categorização representativa, tem-se a subdivisão em tipologias de direitos sociais, políticos e civis:

Quadro 1: Demandas evocadas nas Jornadas de Junho de 2013

\begin{tabular}{|c|c|}
\hline Demanda & Filiação \\
\hline Educação básica de qualida & \multirow{8}{*}{ Direitos sociais } \\
\hline Ensino superior de qualida & \\
\hline Transporte público de qualic & \\
\hline Transporte público gratuit & \\
\hline Emprego e renda & \\
\hline Sistema de saúde de qualidad & \\
\hline Saneamento básico & \\
\hline Segurança pública & \\
\hline \multicolumn{2}{|l|}{ Transparência governamental } \\
\hline Combate à corrupção & \multirow[t]{2}{*}{ Direitos políticos } \\
\hline Destino do investimento público & \\
\hline Liberdade de expressão & \multirow{3}{*}{ Direitos civis } \\
\hline Liberdade de imprensa & \\
\hline Igualdade diante da lei & \\
\hline
\end{tabular}

Fonte: catalogada a partir de Estadão (2013), Folha de S. Paulo (2013) e O Globo (2013).

Os direitos sociais detêm a maior parcela de reivindicações. As pautas sociais têm maior apelo pelos quadros de precariedade e por consistir em dores sociais mais evidentes e que atingem mais diretamente as camadas populares, com acuidade da cobertura midiática. São matérias de longa data e que se tornam agendas políticas nos pleitos eleitorais e nos programas 
O lugar do desenvolvimento na mobilização social: signos de desenvolvimento e produção de utopismos nas jornadas de junho de 2013

de governo. Porém, como a construção do desenvolvimento evoca, são impasses insolúveis à primeira vista.

Direitos políticos e civis têm menor pregnância nos debates de cidadania e consciência de direitos, considerando o extrato brasileiro e latino-americano em geral (CARVALHO, 2000). Todavia, os quadros de corrupção e insatisfação política tomaram os noticiários e a opinião pública, bem como as liberdades garantidas pelos direitos civis. Não só as pautas de arrocho social representam ameaças à vida em sociedade, mas pautas como corrupção, (falta de) transparência pública e liberdade de imprensa passam a ser percebidas.

Essas demandas indexadas em direitos reclamam projetos. As vozes não indicam apenas insatisfações isoladas, mas na acústica de um movimento multiescalar, adquiriu uma consciência territorial difusa, capaz de produzir uma narrativa de disputa ao discurso de governança, política e economia. E não se tratam de meros projetos.

Os projetos de país estão comumente atrelados aos representantes políticos, estes responsáveis pela realização de medidas, projetos, leis e ações que garantam ou gerem desenvolvimento em instâncias municipais, estaduais e nacionais. Isto é, a representação vista como delegação do curso de desenvolvimento e enfraquecimento da cidadania é uma tônica comum dessa discussão.

No entanto, nas redes e na multiescala das Jornadas de Junho de 2013, os projetos de país eram disputados. A princípio, por força da insatisfação popular pelos representantes e pelo quadro político geral, sem força de diálogo com a manifestação (SANTOS; CUNHA, 2019). Mas, por outro lado, projetos de país passaram a representar a conjuntura de projetos de vida, ameaçados conforme a aquiescência das pautas.

A insatisfação política e os projetos de vida em jogo nos projetos de país convivem com a tibieza sociopolítica e cidadã do brasileiro (CARVALHO, 2000). Esse quadro peculiar e sugestivo para contradição parece indicar que há uma nova mecânica de compreensão popular sobre o objeto político, cidadão e, consequentemente, a partir da noção de desenvolvimento.

Gera-se mobilização, insurgência e coalizão na medida em que os projetos de vida postos na vitrine da multiescala e da comunicação (da alternativa comunicação em rede e da tradicional cobertura midiática). Ora, os ideais individuais ou localizados reclamam partes do desenvolvimento prometido de modo messiânico na alternância de agendas políticas. Há que se considerar aqui, tessituras de desenvolvimento (SANTOS; PEREIRA, 2018).

Forma-se um quadro complexo: os impasses do desenvolvimento como programa que abarque os dilemas de uma realidade complexa, a dissidência cidadã, a insatisfação política e a 
disputa de contexto da narrativa sobre os rumos do país, confundidos por uma noção individual, personalizada e de consumo dos produtos sociais como direitos e o bem viver.

Projetos de vida tornam-se projetos mais relevantes do que projetos de país. Tal prospecto é combustível mobilizador. A insurgência torna-se um veículo de eco das vozes marginalizadas pelo ruído político, econômico e midiático. As mobilizações sociais tradicionais não se esvaziam (MANEIRO, 2006), mas tornam-se entrelaçadas a esses novos fluxos de agência e potência.

A querela apresenta-se como um caminho, um índice de transformação. Com a arregimentação da comunicação em rede, fluxos mais eficazes são possíveis. Fomentam-se pulsões utópicas combinadas entre os utopismos do desenvolvimento messiânico e capaz de corrigir cabalmente o objeto do que se objeta na luta e os utopismos da mobilização digital que faz crer no poderio da interconexão como futuro democrático.

A tensão pela meta germinada pelos afetos e as dinâmicas do desenvolvimento e suas centralidades encontra esteira dos utopismos da mobilização em rede (SANTOS; PEREIRA, 2019). A rede, dada a sua fluidez e forma, parece criar ambientes de aderência aos ideais mobilizados, necessidades e visões de mundo. O signo da luta faz crer e vislumbrar para que a tensão encontre repouso em sua meta, em um lugar, o lugar do desenvolvimento.

Signos representam, mas em sua representação e semiose, há promessas. Promessas indicam caminhos que alargam os esforços diante de uma meta suavizada pela narrativa sígnica e utópica. O desenvolvimento e o que dele se desprende como promessa de eficácia, ordenamento, ganhos, bem estar e bem viver torna-se um acontecer utópico da esperança.

Esse plano ideal de vida cresce sob os escombros dos projetos de desenvolvimento perdidos pela lacuna que deixam. Trata-se de um lugar ideal que constitui uma meta inexorável e que as forças representam obstáculos, obstáculos que a insurgência ou outras operações sociopolíticas - como as redes e a comunicação em rede - auxiliam a romper, modificar.

É das redes essa prerrogativa de fluidez que torna a experiência cotidiana um híbrido de concentração e contiguidade, materialidade e virtualidade. Tais características constroem uma performance de liberdade que, em meio aos cenários em dissolução e conflito, fortalecem um plano salvífico diante dos extratos sociais, econômicos e políticos de revés experimentados rotineiramente.

Observa-se um desenho de visão e produção social em que as redes interpolam narrativas transformadoras do lugar do desenvolvimento para um plano sempre mais exequível, possível, válido e desejável. Essa idealização ativa o conteúdo insurgente contemporâneo em 
O lugar do desenvolvimento na mobilização social: signos de desenvolvimento e produção de utopismos nas jornadas de junho de 2013

performances que combinam agência, potência e dinâmicas que desafiam o ordinário do espaço e do tempo.

A disjunção espaço-temporal provocada pela tessitura das redes e no intercurso comunicacional criam utopias de mobilização e utopias de desenvolvimento, questionando o status quo e o modus operandi da participação social. E nisso, o lugar ideal do desenvolvimento se complexifica na medida em que se torna uma dimensão disforme e que se perde na própria idealização, vítima dos cenários sociopolíticos e refém dos signos sedutores da modernidade e do capitalismo que fetichiza agora a subjetividade.

O lugar do desenvolvimento torna-se uma alocação da necessidade de diversos sujeitos participantes de vivências comuns e oriundos de experiências distintas por contextos de escala geográfica e trajetória sócio-histórica. A própria noção de direitos e o conteúdo do que se demanda na luta se metaboliza em um intento que roga pelo bem viver no encantamento dos signos e no desencantamento da realidade do desenvolvimento como meta.

A complexidade do lugar ideal não deriva apenas do problema de uma noção definitiva e quase arquetípica de um desenvolvimento messiânico e hegemônico. É a noção consumível, feita produto e mercantilizada das dimensões que o objeto do desenvolvimento evoca que torna esse cenário desafiador, consome-se signos de desenvolvimento na crença de uma participação social redentora (AVRITZER; COSTA, 2006).

Utopismos são produzidos e alimentados nesse contexto. Na meta tensa por esse lugar ideal, descortina-se uma modalidade particular de perceber e construir desenvolvimento, instalado em micro-ambientes. Produz-se microdesenvolvimentos. As trajetórias locais, particularizadas e inscritas na experiência mais narrativa e comunal são o esteio no qual o pleito das benesses do desenvolvimento passa a dimensionar novas crenças na sociedade, na economia, na política e na cultura.

São exercícios inovadores de sociabilidade e de participação. Ainda que vulnerabilidades sejam prementes e claramente observáveis, há aqui oportunidades de compreender os ditames futuros e dos impasses do que o desenvolvimento significa nesse ponto do zeitgeist. Tem-se diante dos olhos e dos estudos uma oportunidade fascinante, onde o primado do micro sobre o macro provoca e faz refletir sistemas, estruturas, crenças e o próprio eixo do pensamento contemporâneo e interdisciplinar sobre esse conceito volátil. 


\section{CONSIDERAÇÕES FINAIS}

As Jornadas de Junho de 2013 no Brasil, objeto de reflexão neste estudo, se configuram como um evento-fenômeno de insurgência caracterizado pela forma em rede e na pulverização de pautas, cujas demandas abrangentes reclamam direitos e projetos. Projetos que, por sua vez, querem repousar em noções mais amplas como a nação, mas perpassam trajetórias pessoais. São disputas de controle e narrativa do desenvolvimento, do macro para o micro.

Esse novo desenho de articulação popular indica uma flexão da participação, onde as territorialidades de insurgência são tessituras de coalizão e desenvolvimento(s). A ressonância da voz reivindicatória popular em rede indica a subversão das assimetrias do desenvolvimento ou, pelo menos, um sinal de que a planificação do conceito encontra impasses maiores. Microdesenvolvimento é o início de uma discussão possível sobre o quadro atual de ativismos em rede e seu significado ainda provocador acadêmica, política e socialmente.

Os signos de modernidade e do próprio desenho do desenvolvimento tornaram essas articulações produtos consumíveis e que compõem uma performance de participação como um ato de consumo. Ora, signos representam e contém nessa representação promessas. As promessas alimentam o exercício pela produção de utopismos. Desdobra-se uma ambiência instável, ou melhor, flutuante de participação social e de entendimento do significado de porque se participa.

Microdesenvolvimentos são modalidades de um novo acontecer de mobilizações populares, novo acontecer de demandas e um novo acontecer de percepção do desenvolvimento. Do impasse do termo, vislumbra-se uma nova construção que é semântica, mas já se irradia em uma práxis que é sobretudo agência, potência, experiência e vivência.

\section{REFERÊNCIAS}

AVRITZER, L.; COSTA, S. Teoria crítica, democracia e esfera pública: concepções e usos na América Latina. In: DOMINGUES, José Maurício; MANEIRO, Maria (org.). América Latina hoje. rio de Janeiro: Civilização Brasileira, 2006.

BAUDRILLARD, J. A sociedade de consumo. 3. ed. Lisboa: Edições 70, 2009.

BAUMAN, Z. Vida para consumo. A transformação das pessoas em mercadoria. São Paulo: Zahar, 2008.

BERTONCELO, E. R. R. Revisitando os estudos do Desenvolvimento. BIB, São Paulo, n. 71, p. 95-122, jan./jun. 2011. 
O lugar do desenvolvimento na mobilização social: signos de desenvolvimento e produção de utopismos nas jornadas de junho de 2013

CANCLINI, N. G. Consumidores e cidadãos. 6. ed. Rio de Janeiro: Editora UFRJ, 2006.

CARVAlHO, J. M. Cidadania na encruzilhada. In: BIGNOTTO, N. (Org.). Pensar a república. Belo Horizonte: Editora UFMG, 2000. p. 105-130.

CASTELLS, M. Redes de indignação e esperança: movimentos sociais na era da internet. Tradução de Carlos Alberto Medeiros. Rio de Janeiro: Zahar, 2013.

ESTEVA, G. Desenvolvimento. In: SACHS, W. Dicionário do Desenvolvimento: guia para o conhecimento como poder. Petrópolis: Editora Vozes, 2000.

FOLHA DE S. PAULO. São Paulo: Grupo Folha, 2013

IVO, A. B. L. O paradigma do desenvolvimento: do mito fundador ao novo desenvolvimento. Caderno CRH, Salvador, n. 65, p. 187-210, 2012.

MANEIRO, M. Movimentos sociais e Estado: uma perspectiva relacional. In: DOMINGUES, José Maurício; MANEIRO, Maria (org.). América Latina hoje. rio de Janeiro: Civilização Brasileira, 2006.

MARTÍN-BARBERO, J. Projetos de modernidade na América Latina. In: DOMINGUES, José Maurício; MANEIRO, Maria (org.). América Latina hoje. rio de Janeiro: Civilização Brasileira, 2006.

O ESTADO DE SÃO PAULO. São Paulo: Grupo Estado, 2013.

O GLOBO. Rio de Janeiro: Grupo Globo, 2013.

RIST, G. El desarrollo: historia de una creencia occidental. Tradución de Adolfo Fernández Marugán. Madrid, España: Catarata, 2002.

SANTOS, G. S.; CUNHA, M. G. C. C. "Não é por R\$ 0,20, é por direitos": dinâmicas de insurgência nas Jornadas de Junho de 2013 no Brasil. Caminhos de Geografia, Uberlândia, v. 20, n. 69, p. 94-110, jan./mar. 2019.

SANTOS, G. S.; PEREIRA, A. M. Territorialidades de insurgência, tessituras de desenvolvimento(s): participação social e coalizão nas Jornadas de Junho de 2013 no Brasil. Geofronter, Campo Grande, v. 4, n. 4, p. 7-22, set./dez. 2018.

SANTOS, G. S.; PEREIRA, A. M. Utopismo, insurgência e espaço urbano: o "direito à cidade" lefebvriano e as Jornadas de Junho de 2013 no Brasil. Cadernos Metrópole, São Paulo, v. 21, n. 45, p. 461-479, maio/ago. 2019.

Recebido em Janeiro de 2020

Aprovado em Abril de 2020

Publicado em Fevereiro de 2021 